\title{
Influence of areal density on the energy absorbed by thin composite plates subjected to high-velocity impacts
}

\section{Shirley K García-Castillo, Sonia Sánchez-Sáez and Enrique Barbero}

\begin{abstract}
This work analyses the influence that the areal density of a composite thin-plate, made of glass-fibre woven laminates and subjected to high-velocity impact, exerts on perforation-threshold energy, contact time, and energy-absorption mechanisms. The perforation-threshold energy increased with the areal density. Also, the contact time increased at impact energies above the perforation-threshold energy and decreased below this threshold. The main energyabsorption mechanisms at impact energies close to that causing perforation were found to be the deformation and failure of the fibres, regardless of the areal density. For higher impact energies, the main mechanisms were fibre failure and the energy absorbed by acceleration of the laminate.
\end{abstract}

\author{
Keywords \\ High-velocity impact, glass-fibre laminates, modelling
}

Date received: 27 January 2012; accepted: 18 June 2012

\section{Introduction}

The perforation of laminate structures due to transverse dynamic load is a critical subject in different areas of engineering. Although this topic has been widely covered in the literature on the subject, many studies tend to focus on armour-grade composites for ballistic applications. While a structural-grade laminate is not designed as armour, it could be subjected to highvelocity impacts of low-mass fragments, e.g. the impact of a small stone on the structure of a high-velocity train. The good mechanical properties, low manufacturing costs, and permeability to electromagnetic waves of glass-fibre composites, mean that these materials are widely used in aeronautics as well as naval and groundtransport industries. Therefore, the study of the highvelocity impact behaviour of glass-fibre laminates is a key aspect to be considered in structural design.

A laminate absorbs all of the projectile energy up to the impact energy at which penetration begins to occur; after perforation, as the impact energy increases, the absorbed energy decreases. It is important to examine the perforation conditions of a laminate, which can be studied by means of the perforation velocity or perforation energy. The perforation-threshold energy is defined as the energy beyond which a specific projectile perforates the laminate.
The kinetic energy of the projectile is dissipated through several mechanisms. The predominant energyabsorption mechanisms are: elastic deformation of the laminate, frictional energy absorbed during penetration, inertia of the laminate or back-face deformation, damage generation, etc. ${ }^{1,2}$ Typically, the damage mechanism in glass- and carbon-fibre laminates includes delamination, matrix cracking, fibre fracture, and plug punch-out induced by the through-thickness shear. In thin glass-fibre laminates the friction and shear plugging mechanisms are negligible. ${ }^{3}$

The energy-absorption characteristics of a plate subjected to ballistic impact depend on constituent material properties (fibre and matrix), laminate and projectile parameters, and impact conditions. ${ }^{1,4}$ The influence of some of these parameters on the perforation of laminate plates has been studied. . $^{2,3-10}$

Department of Continuum Mechanics and Structural Analysis, University
Carlos III of Madrid, Spain

Corresponding author:

Shirley K García-Castillo, Department of Continuum Mechanics and Structural Analysis, University Carlos III of Madrid, Avda. de la Universidad, 30, Leganés, 2891I, Madrid, Spain.

Email: sgcastil@ing.uc3m.es 
One of the main parameters affecting perforation is laminate thickness. An alternative and related parameter is the areal or surface density (density per square meter) of the laminate. Several authors have studied the influence of these parameters on perforation velocity or the perforation-threshold energy of Kevlar-, carbon- and glass-fibre laminates. ${ }^{2,5-7,9,11-19}$

For armour-grade laminates, a non-linear relationship between perforation-threshold energy and thickness has been suggested. ${ }^{17} \mathrm{Zhu}$ et al. ${ }^{5}$ studied the perforation response of [0/90] Kevlar/polyester laminates impacted by cylindro-conical projectiles. The simplified model used included damage by bulging, delamination, and fibre deformation and failure. Matrix cracking was disregarded. These researchers found that the perforation velocity varies linearly with laminate thickness within the range of 3 to $14 \mathrm{~mm}$. On the contrary, He et al. ${ }^{9}$ stated that there is a non-linear relationship between perforation velocity and thickness for a broad range of thicknesses below $16 \mathrm{~mm}$. They proposed a theoretical model based on the assumption that the strain is localized and that the contact force is velocity dependent. The model was validated with the experimental data from $\mathrm{Zhu}$ et al. ${ }^{5}$

The influences of areal density on perforation velocity or perforation-threshold energy on structural composites, carbon- and glass-laminates, are summarized in Table 1.

On carbon-fibre laminates, several trends have been found in the relationship between perforation-threshold energy and thickness or areal density. A quadratic relationship between the perforation-threshold energy and thickness was experimentally observed by Cantwell and Morton $^{11}$ in $[+45 /-45]$ thin carbon laminates struck by spherical projectiles. Later ${ }^{12}$ they proposed a simple model that included the failure by delamination and shear plugging to reproduce this behaviour within a thickness range of between $0.5 \mathrm{~mm}$ and $4.0 \mathrm{~mm}$. Kasano and $\mathrm{Abe},{ }^{13}$ conducting high-velocity impact tests on orthotropic and quasi-isotropic carbon laminates using spherical projectiles, found a linear relationship between perforation velocities and laminate thickness for both laminates. On the contrary, $\mathrm{He}$ et al., ${ }^{9}$ using a theoretical model, proposed a non-linear relationship between perforation velocity and thickness of up to $10 \mathrm{~mm}$ (corresponding to a non-quadratic relationship between perforation-threshold energy and thickness). These authors validated the model with experimental data from Ulven et al., ${ }^{14}$ who tested woven carbon/epoxy laminates 3.2 and $6.5 \mathrm{~mm}$ thick, impacted by conical-nosed projectiles.

In glass-fibre laminates, both linear and non-linear variations between perforation velocity and thickness were found. Gellert et al. ${ }^{6}$ tested glass-fibre woven laminates of various thicknesses $(4.5-20.0 \mathrm{~mm})$ struck with three nose shapes. A bilinear relationship was found between the perforation-threshold energy and thickness. Proposing a simple model to explain this relationship, these authors affirm that energy absorption in thin glass-reinforced laminates is largely independent of projectile-nose geometry. Wen, ${ }^{7}$ studying the perforation of several thick laminates impacted with projectiles of different mass and geometry, showed the influence of thickness on the perforation velocity. Both linear and non-linear variations were found. For example, for an E-glass/polyester struck by a flat-faced, low-mass projectile, this latter researcher found a linear relationship and a non-linear relationship when the mass and diameter of the projectile increased. A similar behaviour was found for hemispherical-ended projectiles. Deka et al. ${ }^{2}$ applied a numerical model to analyse the damage evolution on E-glass/polypropylene laminates with several levels of thickness subjected to high-velocity impacts of cylindrical flat-nosed projectiles. These authors used a progressive-failure model based on Hashin criteria in order to estimate the energy absorbed by the laminate. A non-linear relationship was found between perforation velocity and thickness. Also, He et al., ${ }^{9}$ using a theoretical model, proposed a non-linear relationship between perforation velocity and thickness for glass-fibre laminates less than $7 \mathrm{~mm}$ thick. On the contrary, Naik et al. ${ }^{15}$ found a linear variation for woven e-glass/epoxy laminates, in a thickness range from 1.0 to $2.6 \mathrm{~mm}$, when it was impacted by flat

Table I. Influence of the areal density on the perforation-threshold energy and perforation velocity.

\begin{tabular}{|c|c|c|}
\hline & \multicolumn{2}{|l|}{ Carbon-fibre laminates } \\
\hline & Perforation-threshold energy/areal density relationship & Perforation velocity/areal density relationship \\
\hline \multirow[t]{3}{*}{$\begin{array}{l}\text { Cantwell and Morton } \\
\text { He et al. } \\
\text { Kasano and } \mathrm{Abe}^{13} \\
\text { Kan }\end{array}$} & Quadratic & $\begin{array}{l}\text { Non-linear } \\
\text { linear }\end{array}$ \\
\hline & Glass-fibre laminates & \\
\hline & Perforation-threshold energy/areal density relationship & Perforation velocity/areal density relationship \\
\hline $\begin{array}{l}\text { Gellet et al. } \\
\text { Wen }^{7} \\
\text { Deka et al. } \\
\text { He et al. } \\
\text { Naik et al. } \\
\text { Na }\end{array}$ & Bi-linear & $\begin{array}{l}\text { Linear and non-linear }{ }^{a} \\
\text { Non-linear } \\
\text { Non-linear } \\
\text { Linear }\end{array}$ \\
\hline
\end{tabular}

a: Depend of mass and diameter of projectile. 
projectiles. These researchers applied an analytical model, based on energy considerations, in order to predict the variation of perforation velocity as a function of thickness.

In the literature on the subject, only the influence of the thickness or areal density on perforation velocity or perforation-threshold energy has been studied, and contradictory results have been found for this relationship; that is, a linear as well as a non-linear relationship has been found in structural-grade laminates. No information concerning the influence of areal density on the energy-absorption mechanism is available in the literature. The aim of the present work was, therefore, to analyse the influence of areal density on perforationthreshold energy, contact time, and energy-absorption mechanisms for thin glass-fibre woven laminates. The analytical model applied was previously developed and validated. $^{20-22}$ The advantages of these kinds of models lie in their low computational cost and in their ability to explicitly describe the physical behaviour of the laminate.

\section{Model description}

\section{Hypothesis}

This model, developed for plain woven laminates of GFRP, is based on energy-conservation laws. As in the proposals of Moyre et al. ${ }^{1}$ and Naik et al., ${ }^{3,16,23}$ the model considers several energy-absorption mechanisms. It assumes that the plate absorbs energy by way of three mechanisms: the elastic deformation of the fibres; the acceleration of the plate; and the generation of damage in the laminate (this damage can be due to failure of fibres, delamination, and matrix cracking). In the development of the model, the following hypotheses were considered:

(a) the projectile was spherical and perfectly rigid;

(b) the material showed a linear elastic behaviour;

(c) the energy absorbed by shear plugging was negligible, because this phenomenon was not detected in experimental tests of thin glass-fibre laminates;

(d) the energy absorbed by friction between the laminate and the projectile, and the heat generated, were not included in the model because the laminate under consideration is very thin;

(e) the velocities of longitudinal and transversal wave were constant in the laminate thickness.

\section{Energy-absorption mechanisms}

Given the energy conservation between two instants in time, such as the initial instant $\left(t_{0}\right)$ and a generic instant $(t)$

$$
E_{K C_{0}}=E_{K C}(t)+E_{A B}(t)
$$

where $E_{K C_{0}}$ is the impact energy, and $E_{K C}$ and $E_{A B}$ are, respectively, the kinetic energy of the projectile and the absorbed energy of the plate at each instant in time. The latter includes the energy absorbed by the elastic deformation of fibres $\left(E_{E D}\right)$, the energy absorbed by acceleration of the laminate $\left(E_{K L}\right)$, and the energy absorbed by failure of the laminate $\left(E_{F L}\right)$

$$
E_{A B}(t)=E_{K L}(t)+E_{E D}(t)+E_{F L}(t)
$$

The energy absorbed by the failure of the laminate includes: energy absorbed by failure of fibres $\left(E_{T F}\right)$, delamination $\left(E_{D L}\right)$, and matrix cracking $\left(E_{M C}\right)$

$$
E_{F L}(t)=E_{T F}(t)+E_{D L}(t)+E_{M C}(t)
$$

Relatively simple expressions for each energy-absorption mechanism are proposed. A detailed description of these expressions can be found in García-Castillo et al. ${ }^{20,21}$

\section{Energy absorbed by laminate acceleration}

In the development of this model, it was assumed that the laminate and the projectile are always in contact during the impact. Due to the impact, a portion of the laminate is accelerated at the same velocity as the projectile. Since the laminate considered is thin, this model assumes a constant velocity through the laminate thickness.

\section{Energy absorbed by fibre failure}

In woven laminates, the fibres are grouped in assemblies called yarns, composed of several individual filaments. In this model, failure is assumed to occur only in the yarns directly below the projectile, which offer resistive force against the penetration of the projectile. The maximum strain criterion is assumed for fibre failure.

The energy absorbed by failure of fibres is calculated by assuming that the projectile diameter is smaller than the width of the yarn, so that the impact occurs only on one yarn.

It should be noted that a stress wave attenuation is generated due to the transmission and reflection of waves in the impacted laminate. The effect of this phenomenon on the energy absorbed by fibre failure is summarized in the stress-wave-transmission factor, which depends on the geometry of the fabric as well as the mechanical and physical properties of the fibre and the matrix. Usually, the stress-wave-transmission factor is less than one. ${ }^{24}$

\section{Energy absorbed by elastic deformation of fibres}

The fibres deformed elastically during impact lie within the region affected by the transversal stress wave generated by the impact. This region is localized between the projectile diameter and the distance covered by the transversal waves. 
The strain is assumed to be a linear function of the radial position, from the impact point to the distance covered by the transversal wave, so that the fibres close to the impact point are subject to a deformation equal to the failure strain, whereas the fibres away from the impact point show a strain equal to zero.

\section{Energy absorbed by delamination and matrix cracking}

In this model, it is assumed that the energy absorbed due to damage by delamination and matrix cracking is a result of the distance covered by transversal waves on the laminate.

It was assumed that the area that contributes to the absorption mechanism by delamination and matrix cracking is approximately equal to a circular surface, as shown by the image obtained by the non-destructive inspection of García-Castillo et al. ${ }^{8}$

Damage due to delamination is related to the critical dynamic-strain energy-release rate in mode II; and the damage by matrix cracking with the energy absorbed by matrix cracking per unit volume.

\section{Model resolution}

From these expressions and equation (1), the following differential equation can be derived

$$
\begin{aligned}
v(t) \cdot & {\left[m_{p}+\pi \cdot A_{D} \cdot v_{T}^{2} \cdot t^{2}\right] \cdot \frac{d v(t)}{d t} } \\
& +\pi \cdot A_{D} \cdot v_{T}^{2} \cdot t \cdot v^{2}(t)+h(t) \cdot v(t)=g(t)
\end{aligned}
$$

where $v(t)$ is the projectile velocity at each instant of time, $A_{D}$ the areal density, $m_{p}$ the mass of projectile, $v_{T}$ the velocity of the transversal wave generated by the impact on the plate, and $h(t)$ and $g(t)$ are known functions, defined as

$$
\begin{aligned}
h(t) & =\frac{\varepsilon_{r}^{2} \cdot B^{2} \cdot E}{2 \cdot \ln b} \cdot\left[1-b^{\left(4 \cdot v_{L} \cdot t / B\right)}\right] \\
g(t) & =-\left[\left(\frac{E \cdot e \cdot \varepsilon_{r}^{2}}{48} \cdot\right.\right. \\
\left.\frac{88 \cdot v_{T}^{3} \cdot t^{3}-44 \cdot \phi \cdot v_{T}^{2} \cdot t^{2}-22 \cdot \phi^{2} \cdot v_{T} \cdot t+5 \cdot \phi^{3}}{\left(\phi-2 \cdot v_{T} \cdot t\right)^{2}}\right) & \\
& \left.+2 \cdot\left(G_{I I C D}+E_{M T} \cdot e\right) \cdot v_{T} \cdot t\right] \cdot \pi \cdot v_{T}
\end{aligned}
$$

where $B$ is the yarn width, $b$ the stress-wave transmission factor, $E$ the Young modulus, $E_{M T}$ the energy absorbed by matrix cracking per unit volume, $G_{I I C D}$ the critical dynamic-strain energy-release rate in mode II, $\varepsilon_{r}$ the failure strain, and $\varphi$ the projectile radius.

Equation (4) is a non-linear differential equation that was solved numerically, with the initial conditions $v(0)=v_{0}$ (impact velocity). A finite-difference scheme was employed to solve this equation, estimating the time course of projectile velocity, $v(t)$. The integration of equation (5) was stopped when there was either perforation, or the projectile velocity was zero.

The condition for perforation is defined as

$$
\begin{aligned}
t= & t_{c}, w\left(t_{c}\right)=e, v\left(t_{c}\right)=v_{R} \text {, then the absorbed } \\
& \text { energy is equal to } E_{K C_{o}}-\frac{1}{2} \cdot m_{p} \cdot v_{R}^{2}
\end{aligned}
$$

where $w\left(t_{c}\right)$ is the projectile displacement at $t_{c}$. And the condition for projectile detention is

$$
\begin{aligned}
t= & t_{c}, v\left(t_{c}\right)=0, \text { so that the absorbed } \\
& \text { energy is equal to } E_{K C_{o}}
\end{aligned}
$$

where $v_{R}$ is the residual velocity of projectile and $t_{c}$ is the contact time between the projectile and the laminate.

When equation (4) is solved, the energy absorbed by each mechanism as a function of time can be estimated.

The analytical model has been validated and applied previously to study composite structures subjected to high-velocity impact under different conditions. ${ }^{20-22}$

\section{Results}

The model was evaluated on E-glass/polyester laminates with different areal densities (from $0.7 \mathrm{~kg} / \mathrm{m}^{2}$ to $11.1 \mathrm{~kg} / \mathrm{m}^{2}$ ), which were impacted by a spherical steel projectile with a diameter of $7.5 \mathrm{~mm}$ and a mass of $1.725 \mathrm{~g}$. The properties of E-glass/polyester laminate are listed in Table $2 .^{25}$

The variations of the absorbed energy with the impact energy for two laminates of different areal density, $6.3 \mathrm{~kg} / \mathrm{m}^{3}$ and $11.1 \mathrm{~kg} / \mathrm{m}$, are shown in Figure 1 . These two values were selected because the model was previously compared with experimental results for both areal densities. ${ }^{8,26}$ For both laminates, it can be seen that for impact energy below the perforation threshold the absorbed energy is a linear function of the impact energy, because all the energy of the projectile is absorbed. For these impact energies, the main mechanisms of absorbed energy are the fibre elastic deformation and the fibre failure. However, for impact energy above the threshold, the main mechanism of absorbed

Table 2. Mechanical properties of E-glass/polyester laminate.

\begin{tabular}{lll}
\hline Mechanical properties & $\begin{array}{l}\text { Strain rate } \\
\varepsilon=10^{-4} \mathrm{~s}^{-1}\end{array}$ & $\dot{\varepsilon}=10^{3} \mathrm{~s}^{-1}$ \\
\hline Areal density $\left(\mathrm{kg} / \mathrm{m}^{2}\right)$ & $0.7-1 \mathrm{I} . \mathrm{I}$ & \\
Young modulus $(\mathrm{GPa})$ & 10.13 & 15.20 \\
Mechanical strength $(\mathrm{MPa})$ & 367.39 & 1102.00 \\
Ultimate strain & 0.0357 & 0.0725 \\
Poisson ratio & 0.16 & - \\
Critical dynamic-strain & 3000 & \\
energy-release rate in mode $\mathrm{II}\left(\mathrm{J} / \mathrm{m}^{2}\right)$ & & \\
Wave-transmission factor & 0.90 & \\
Matrix-cracking energy & 106 & \\
per unit volume $\left(\mathrm{J} / \mathrm{m}^{3}\right)$ & & \\
\hline
\end{tabular}




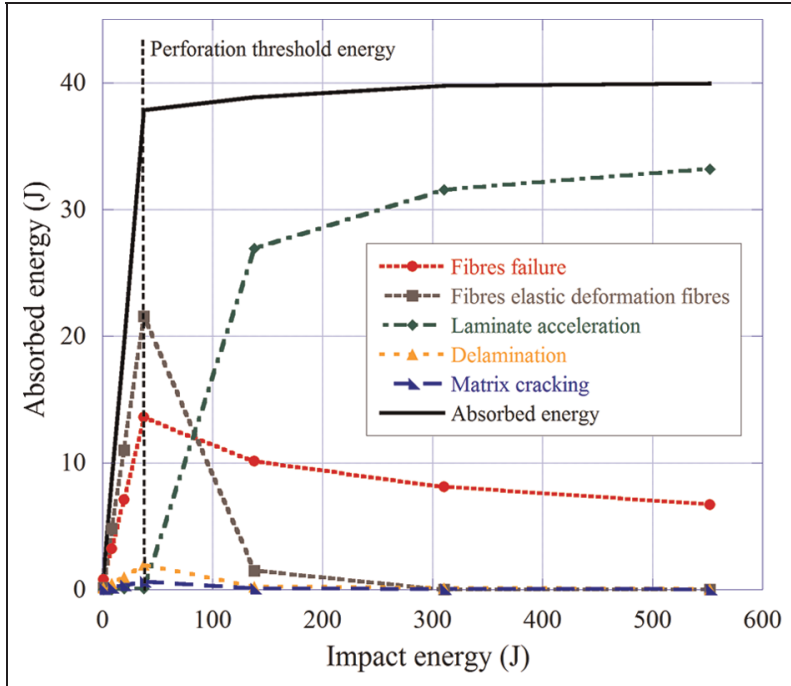

(a)

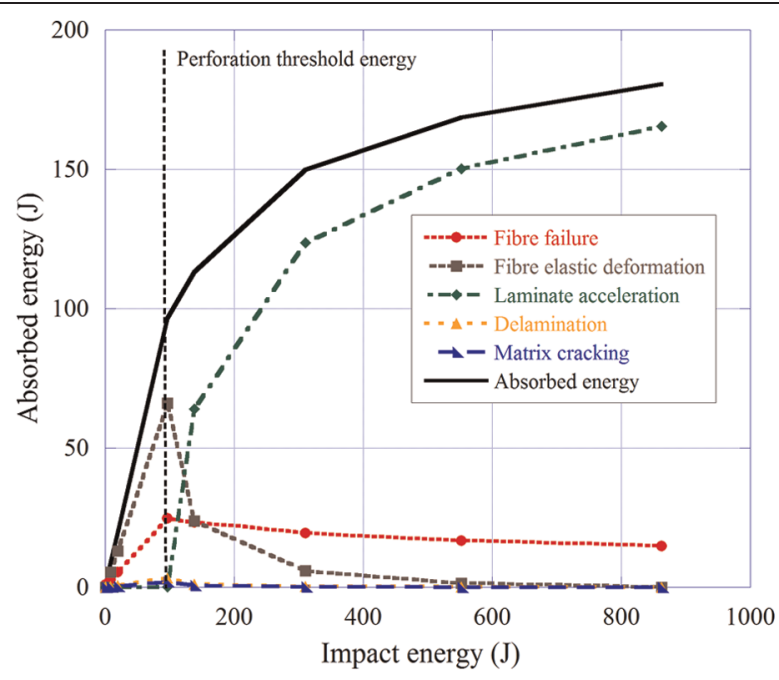

(b)

Figure I. Absorbed energy by a laminate of: (a) $6.3 \mathrm{~kg} / \mathrm{m}^{2}$ areal density and (b) $1 \mathrm{I} . \mathrm{I} \mathrm{kg} / \mathrm{m}^{2}$ areal density.

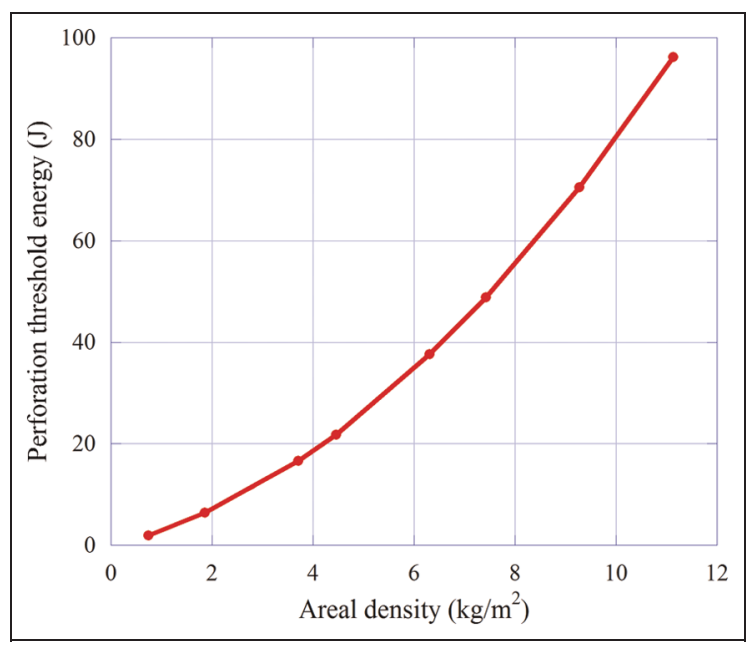

Figure 2. Perforation-threshold energy versus areal density.

energy is the acceleration of the laminate following fibre failure. At impact velocities over the perforation velocity, the energy due to laminate acceleration is high, because this energy is proportional to the square of the impact velocity. Other mechanisms, such as the energy absorbed by delamination and matrix cracking, are negligible for any impact energy. The latter mechanisms and the energy absorbed by fibre elastic deformation diminish with impact velocity above the perforationthreshold energy, because these mechanisms are proportional to the distance covered by the transversal waves, and this distance reduces when the impact velocity accelerates.

The influence of areal density on the perforationthreshold energy, the contact time between the projectile and laminate during the impact, and the energy absorbed by the different failure mechanisms, were also analysed. For the analysis of the variation in the contact time and the energy absorbed by each mechanism with regard to areal density, several impact energies were selected: one that was equal to the perforationthreshold energy, one that did not result in perforation for the entire range of the areal density considered $(1 \mathrm{~J})$, and one that resulted in perforation in the same range of areal densities (550 J). An absorbed-energy ratio was defined as the energy absorbed by each mechanism divided by the impact energy.

The variation in the perforation-threshold energy with the areal density is shown in Figure 2. An increase in areal density, and therefore in the thickness of the laminate, or an increase in laminate density, augments the perforation-threshold energy. The data adjusted accurately to a parabolic curve $\left(\mathrm{R}^{2}=1\right)$ (corresponding to a linear relationship between perforation velocity and areal density). A similar behaviour was described by other researchers for Kevlar-fibre laminates. ${ }^{5}$ This result contradicts those of other authors who propose a non-linear relationship between perforation velocity and areal density. ${ }^{2,9}$

For an impact energy equal to the perforationthreshold energy, the variation of the contact time between the projectile and the plate with the areal density is shown in Figure 3. The contact time increases with the areal density, adjusting well to a square-root curve $\left(\mathrm{R}^{2}=0.9978\right)$.

In Figure 4, for an impact energy of $550 \mathrm{~J}$, the contact time increases with the square of the areal density $\left(R^{2}=0.9990\right)$. However, for impact energy of $1 \mathrm{~J}$, the contact time decreases. This latter relationship can be fit to an inverse square $\operatorname{root}\left(\mathrm{R}^{2}=0.9978\right)$.

At impact energies over perforation $(550 \mathrm{~J})$ the projectile finds more material to perforate when areal density increases and therefore the contact time lengthens.

Below the perforation, the contact time is the time needed to stop the projectile; when the areal density 


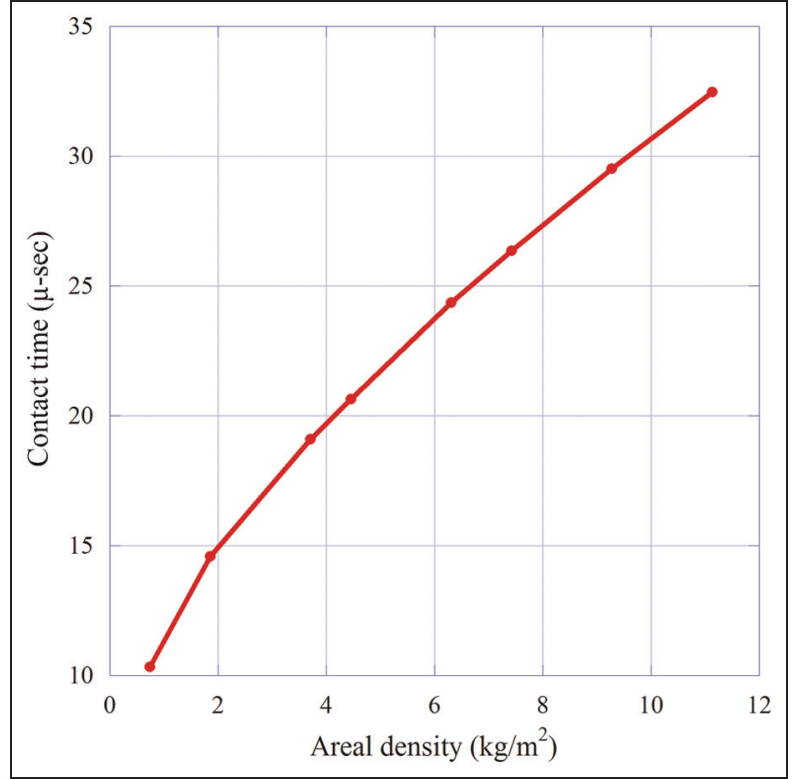

Figure 3. Contact time versus areal density at the perforationthreshold energy.

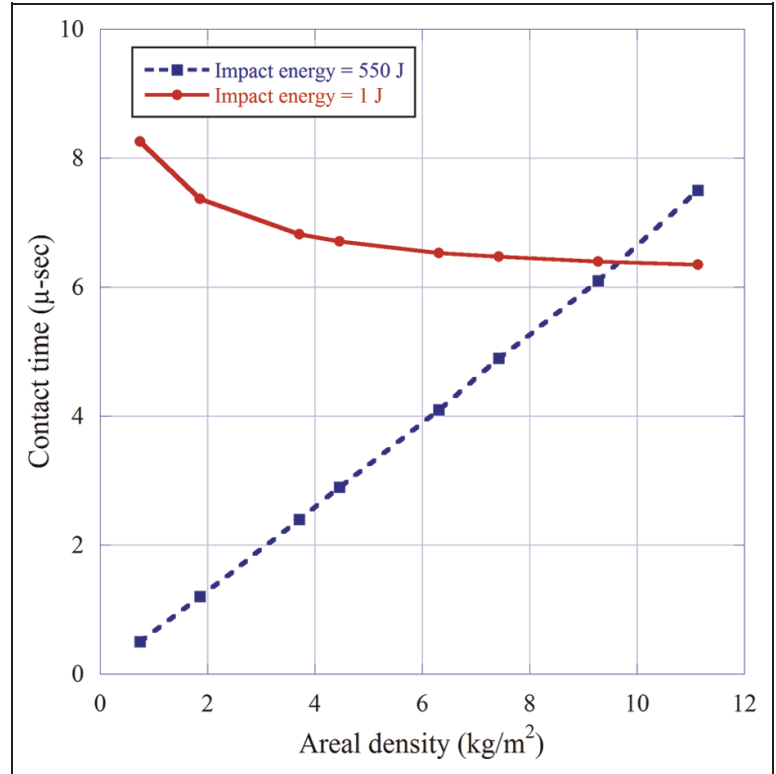

Figure 4. Contact time versus areal density at two impact energies: I J and $550 \mathrm{~J}$.

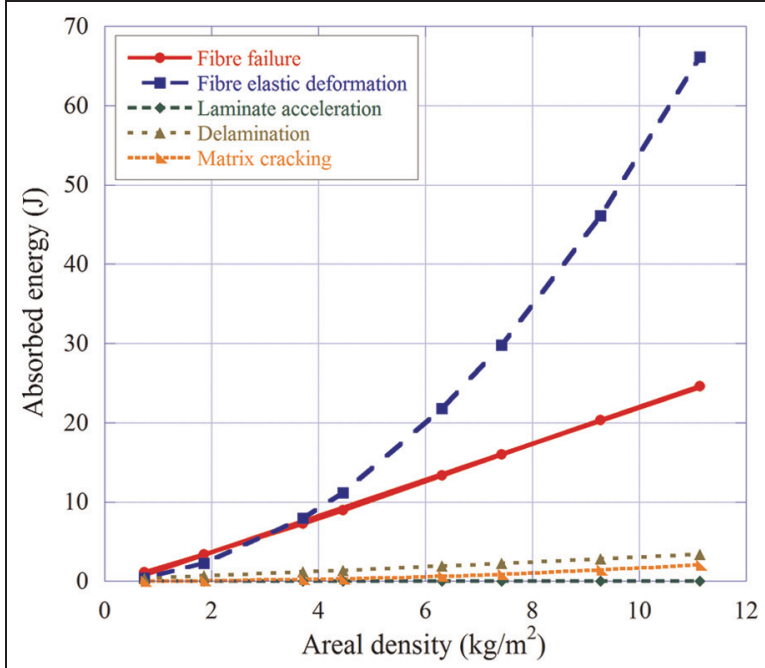

(a)

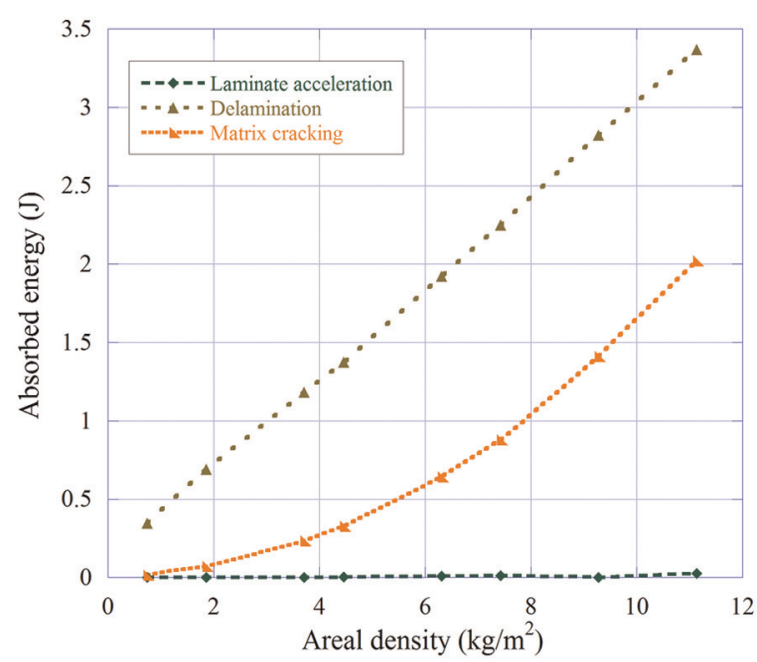

(b)

Figure 5. Absorbed energy versus areal density at the perforation-threshold energy. (a) Energy absorbed by all mechanisms. (b) Energy absorbed by accelerating the laminate, delamination, and matrix cracking.

augments, the total energy absorbed by the laminate also augments (Figure 7, see later), and thus the projectile is stopped in a shorter time.

In Figure 5, the influence of areal density on each energy-absorption mechanism is indicated for impact energy equal to the perforation-threshold energy. Because in this case the impact energy at perforation threshold differed for each areal density (see Figure 2), both the absorbed energy (in Joules) and the absorbedenergy ratio are represented. The two main energyabsorption mechanisms are fibre elastic deformation and fibre failure (Figure 5(a)); both increased with the areal density. The first increased with areal density following a square-root curve $\left(R^{2}=1\right)$, while the second adjusted to a linear relationship $\left(\mathrm{R}^{2}=0.9996\right)$. The energy absorbed by fibre elastic deformation was greater because this mechanism is proportional to the thickness of the laminate and thus increased with the areal density; it is also proportional to the distance covered by the transversal waves that also lengthens because the contact time increases with areal density (Figure 3). The energy absorbed by fibre failure is also greater because this mechanism increases with the contact time, Figure 3. For areal densities higher than $3 \mathrm{~kg} / \mathrm{m}^{2}$ the energy absorbed by fibre elastic deformation was greater than the energy absorbed by fibre 


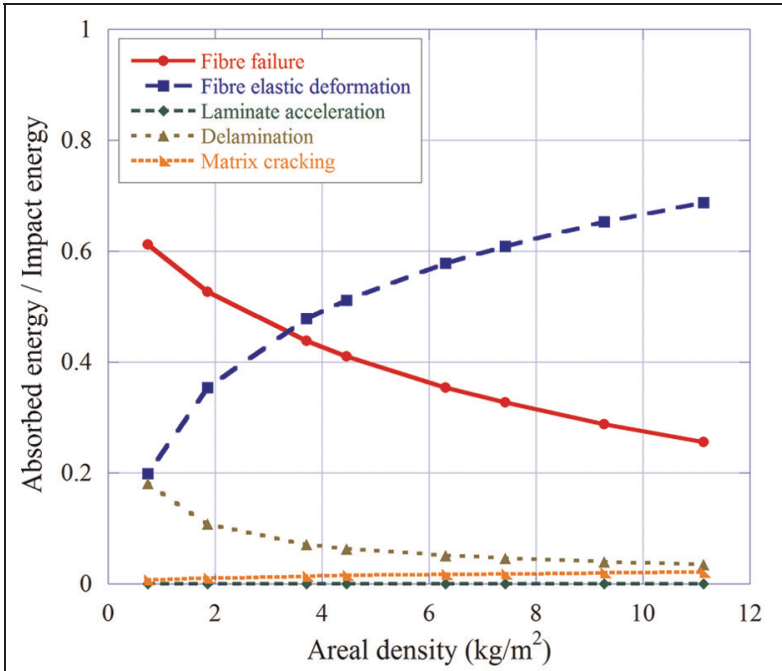

(a)

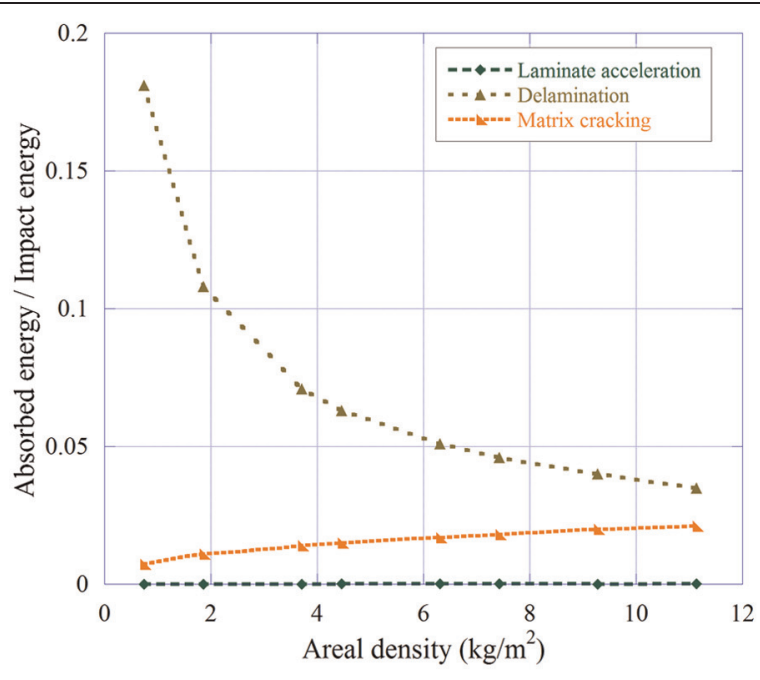

(b)

Figure 6. Absorbed-energy ratio versus areal density at the perforation-threshold energy. (a) Absorbed-energy ratio by all mechanisms. (b) Absorbed-energy ratio by accelerating the laminate, delamination, and matrix cracking.

failure. The other mechanisms are less relevant; especially the energy absorbed by accelerating the laminate that is negligible for any areal density (Figure 5(b)). This mechanism is proportional to the areal density, and thus increases with greater areal density. The energy absorbed by delamination and matrix cracking augmented with the areal density according to a linear relationship $\left(\mathrm{R}^{2}=0.9997\right)$ for the first mechanism and a parabolic curve $\left(R^{2}=0.9999\right)$ for the second. Both mechanisms are proportional to the contact time, which increases at the perforation-threshold energy.

The influence of areal density on the absorbed-energy ratio at the perforation-threshold energy was studied (Figure 6). In this case, the absorbed-energy ratio by the fibre failure and fibre elastic deformation behaved differently when the areal density increased, because the first mechanism diminished and the second augmented (Figure 6(a)). Also, the energy absorbed by matrix cracking incremented slightly (Figure 6(b)). These trends were due to the fact that both mechanisms (fibre elastic deformation and matrix cracking) were proportional to the areal density and the distance travelled by the transverse waves generated by impact, this increasing with contact time, as can been seen in Figure 3. By contrast, the absorbed-energy ratio by delamination diminished with the areal density (Figure 6(b)). The absorbedenergy ratio by acceleration of the laminate is negligible.

The influence of the areal density on the energy absorbed by each of the mechanisms for impact energies of $1 \mathrm{~J}$ and $550 \mathrm{~J}$ is shown in Figures 7 and 8 , respectively. In both cases the energy absorbed by fibre failure increases with the areal density, since this energy is directly proportional to the areal density.

For impact energy of $1 \mathrm{~J}$ (Figure 7), the main energyabsorption mechanism is fibre failure, the acceleration of the laminate being negligible. The energy absorbed by fibre elastic deformation diminishes to negligible values when the areal density increases (Figure 7(b)). This energy-absorption mechanism is controlled by the distance travelled by the transverse waves that is directly proportional to contact time. As reflected in Figure 4, this time shortens with the areal density.

At impact energy of $1 \mathrm{~J}$, the energy absorbed by delamination diminishes with the areal density, whereas that absorbed by matrix cracking increases (Figure 7(b)). Both energies are proportional to the square of the distance travelled by the transverse waves, which diminishes; whereas the second is also proportional to the areal density. From the observed behaviour of the energy absorbed by matrix cracking, it can be deduced that the influence of distance travelled by the transverse waves is less relevant than that of the areal density.

For impact energy above the perforation-threshold energy in a thin woven laminate of glass fibres, some researchers ${ }^{3,20}$ have found that the main energyabsorption mechanisms are fibre failure and the acceleration of the laminate. In this study, for the range of areal density studied, the main mechanisms of energy absorption were the same (Figure 8).

At impact energy of $550 \mathrm{~J}$, the energy absorbed by the acceleration of the laminate increased with the areal density. This trend resulted from the increment of the volume of laminate accelerated, due to the longer distance travelled by the transverse waves and the areal density. The distance travelled by the transverse waves lengthened because it was proportional to the contact time, which increased with the areal density (Figure 4). The least relevant mechanisms were fibre elastic deformation, delamination, and matrix cracking (Figure 8(b)).

\section{Conclusions}

An analytical model was used to analyse the variation with areal density of perforation-threshold energy, 


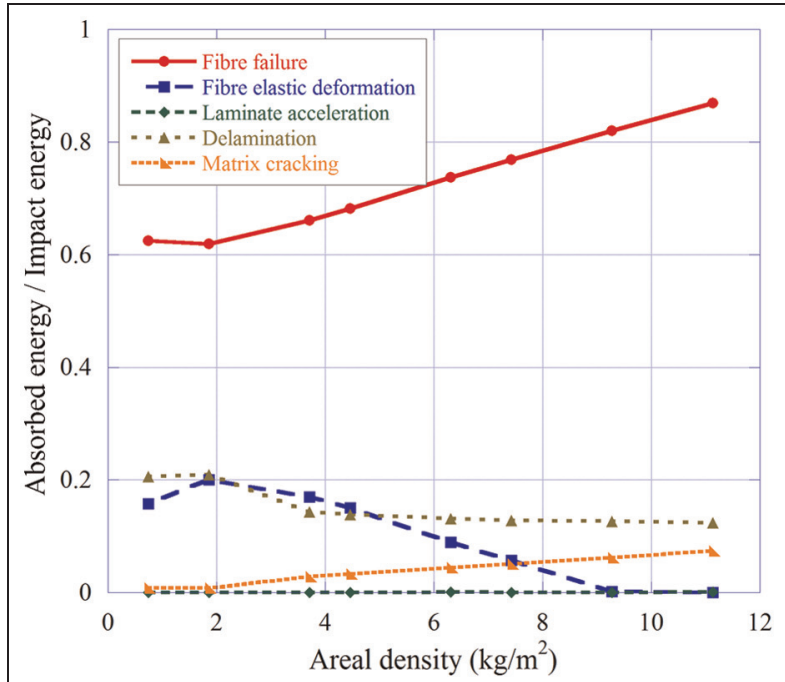

(a)

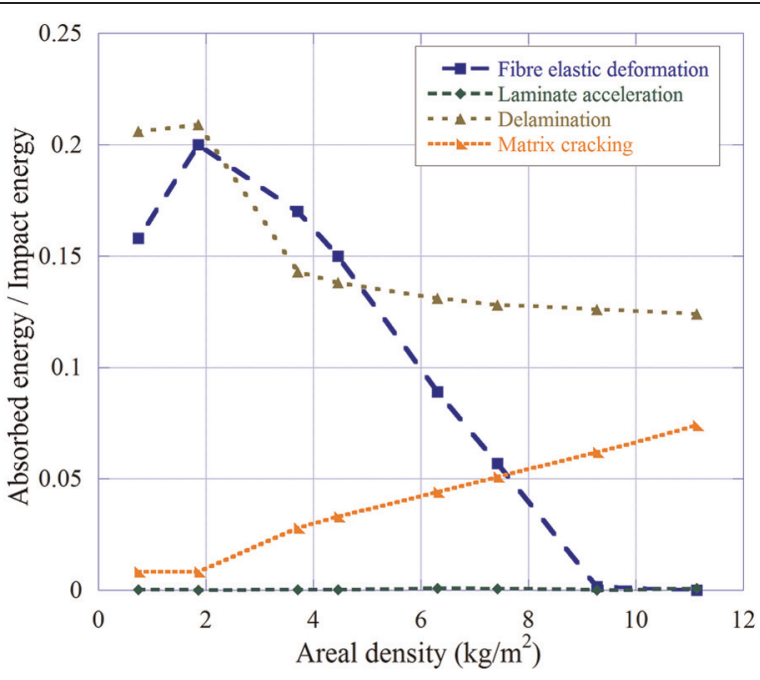

(b)

Figure 7. Absorbed-energy ratio versus areal density at an impact energy of I J. (a) Absorbed-energy ratio by all mechanisms. (b) Absorbed-energy ratio by accelerating the laminate, fibre elastic deformation, delamination and matrix cracking.

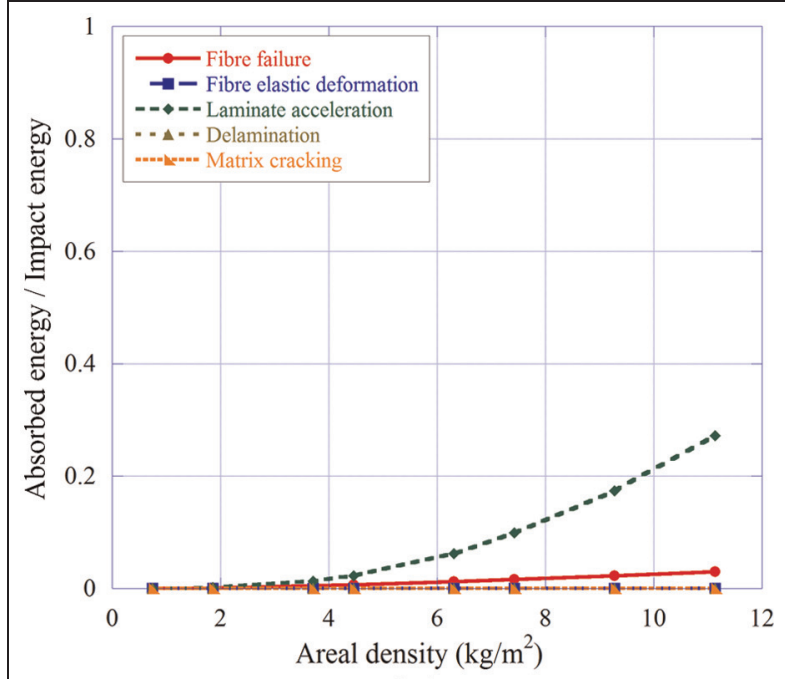

(a)

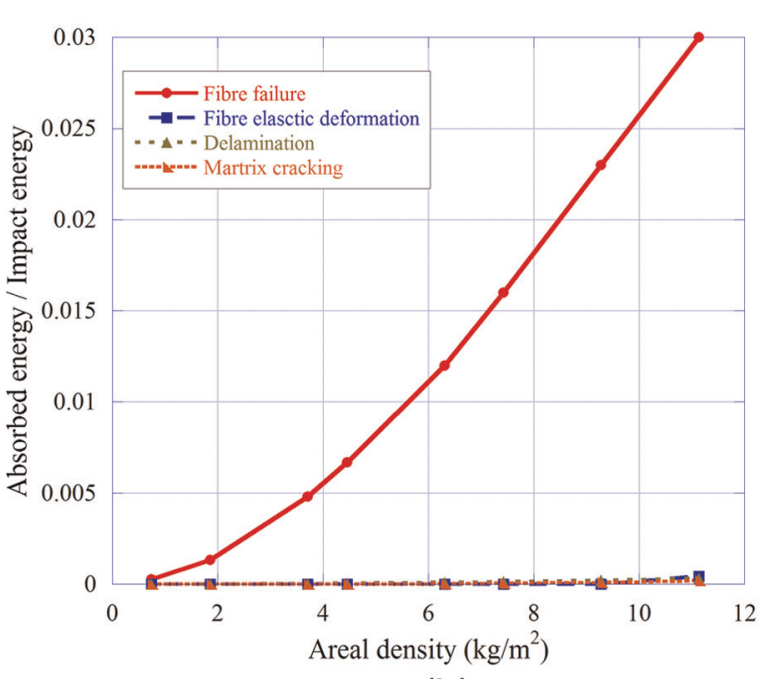

(b)

Figure 8. Absorbed-energy ratio versus areal density at an impact energy of $550 \mathrm{~J}$. (a) Absorbed-energy ratio by all mechanisms. (b) Absorbed-energy ratio fibre failure, fibre elastic deformation, delamination, and matrix cracking.

contact time, and energy-absorption mechanisms in thin glass-fibre laminates subjected to high-velocity impacts. The main conclusions of this work are:

(a) greater perforation-threshold energy was found when the areal density increased with a quadratic relationship;

(b) at impact energies below the perforation-threshold energy, the contact time decreased, whereas at impact energies over this threshold the time increased;

(c) the main energy-absorption mechanism was fibre failure at impact energies that did not result in plate perforation and the acceleration of the laminate for impact energies over the perforation-threshold energy, regardless of areal density;

(d) for impact energies close to the perforationthreshold energy the main energy-absorption mechanisms were fibre failure and fibre elastic deformation.

\section{Funding}

This study was supported by the Autonomous Community of Madrid and the University Carlos III of Madrid (Project CCG10-UC3M/DPI-4694). 


\section{References}

1. Morye SS, Hine PJ, Duckett RA, et al. Modelling of the energy absorption by polymer composites upon ballistic impact. Compos Sci Technol 2000; 60: 2631-264.

2. Deka LJ, Bartus SD and Vaidya UK. Damage evolution and energy absorption of E-glass/polypropylene laminates subjected to ballistic impact. J Mater Sci 2008; 43: 4399--4410.

3. Naik NK, Shrirao, P and Reddy BCK. Ballistic impact behaviour of woven fabric composites: Formulation. Int J Impact Eng 2006; 32: 1521-1552.

4. Cunnif PM. An analysis of the system effects in woven fabrics under ballistic impact. Text Res $J$ 1992; 62: 495-509.

5. Zhu G, Goldsmith W and Dharan CKH. Penetration of laminated Kevlar by projectiles-II. Analytical model. Int J Solids Struct 1992; 29: 421-436.

6. Gellert EP, Cimpoeru SJ. and Woodward RL. A study of the effect of target thicknesss on the ballistic perforation of the glass-fibre-reinforced plastic composites. Int $J$ Impact Eng 2000; 24: 445-456.

7. Wen HM. Penetration and perforation of thick FRP laminates. Compos Sci Technol 2001; 61: 1163-1172.

8. García-Castillo SK, Sanchez-Saez S, Barbero E., et al. Response of pre-loaded laminate composite plates subject to high velocity impact. $J$ Phys IV 2006; 134: $1257-1263$.

9. He T, Wen HM and Qin Y. Penetration and perforation of FRP laminates struck transversely by conical-nosed projectiles. Compos Struct 2007; 81: 243-252.

10. He T, Wen HM and Qin Y. Finite element analysis to predict penetration and perforation of thick FRP laminates struck by projectiles. Int $J$ Impact Eng 2008; 35: 27-36.

11. Cantwell WJ and Morton J. Comparison of the low and high velocity impact response of CFRP. Composites 1989; 20: $545-551$.

12. Cantwell WJ and Morton J. Impact perforation of carbon fibre reinforced plastic. Compos Sci Technol 1990; 38: 119-141.

13. Kasano H and Abe K. Perforation characteristics prediction of multi-layered composite plates subjected to high velocity impact. Proc ICCM-11 1997; 2: 522-531.
14. Ulven C, Vaidya UK and Hosur MV. Effect of projectile shape during ballistic perforation of VARTM carbon/ epoxy composite panels. Compos Struct 2003; 61: $143-150$.

15. Naik NK, Shrirao P and Reddy BCK. Ballistic impact behavior of woven fabric composites: Parametric Studies. Mater Sci Eng A-Struct Mater Prop Microstruct Process 2005; 412: 104-116.

16. Gama BA and Gillespie JW. Punch shear based penetration model of ballistic impact of thick-section composites. Compos Struct 2008; 86: 356-369, 2008.

17. Grujicic M, Glomski PS, He T, et al. Material modeling and ballistic-resistance analysis of armor-grade composites reinforced with high-performance fibers. $J$ Mater Eng Perform 2009; 18: 1169-1182.

18. Gama BA and Gillespie JW. Finite Element Modeling of Impact, Damage and Penetration of Thick-Section Composites. Int J Impact Eng 2011; 38: 181-197.

19. Manzella AF, Gama BA and Gillespie Jr JW. Effect of Punch and Specimen Dimensions on the Confined Compression Behavior of S-2 glass/epoxy composites. Compos Struct 2011; 93: 1726-1737.

20. García-Castillo SK, Sanchez-Saez S, López-Puente J, et al. Impact behaviour of preloaded glass/polyester woven plates. Compos Sci Technol 2009; 69: 711-717.

21. García-Castillo SK, Sánchez-Sáez S and Barbero E. Nondimensional analysis of ballistic impact on thin woven laminate plates. Int J Impact Eng 2012; 39: 8-15.

22. García-Castillo SK, Buitrago BL and Barbero E. Behavior of sandwich structures and spaced plates subjected to high-velocity impacts. Polym Compos 2011; 32: 290-296.

23. Naik NK and Shrirao P. Composite structures under ballistic impact. Compos Struct 2004; 66: 579-590.

24. Roylance D. Stress wave propagation in fibres: Effect of crossovers. Fibre Sci Technol 1980; 13: 385-395.

25. García Castillo SK. Análisis de laminados de materiales compuestos con precarga en su plano y sometidos a impacto. PhD Thesis. University Carlos III of Madrid, Spain, 2007. In Spanish.

26. Buitrago BL, García-Castillo SK and Barbero E. Experimental analysis of perforation of glass/polyester structures subjected to high-velocity impact. Mater Lett 2010; 64: 1052-1054. 